\title{
O ensino da língua egípcia clássica no Brasil: desafios e possibilidades usando recursos digitais
}

\author{
Teaching Ancient Egyptian Language in Brazil: Challenges and \\ Opportunities of Digital Resources
}

\section{Ronaldo Guilherme Gurgel Pereira*}

ronaldo.gurgel@yahoo.de

https://orcid.org/0000-0002-8457-6220

\author{
Thais Rocha da Silva** \\ thais.rochadasilva@hmc.ox.ac.uk \\ https://orcid.org/0000-0003-0616-1924
}

\begin{abstract}
Resumo
Este artigo apresenta os resultados iniciais de um projeto mais amplo sobre o ensino da língua egípcia no Brasil por meio de recursos digitais. Examinamos a primeira etapa através do curso Introdução ao Egípcio Clássico (Egípcio Médio), o primeiro curso online de ensino da língua egípcia no Brasil, tendo em vista a desafiadora realidade para a formação de egiptólogos no país. A partir do debate das Humanidades Digitais, que problematiza a produção e a divulgação do conhecimento nas ciências humanas com recursos tecnológicos, apontamos possíveis caminhos para a expansão deste projeto no cenário brasileiro. Neste escopo, a discussão sobre as plataformas digitais e o ensino de história antiga no Brasil entram como elementos importantes na contextualização desta iniciativa.
\end{abstract}

Palavras-chave: Egiptologia; Humanidades digitais; Hieróglifos; História antiga; Educação.

\section{Abstract}

This paper presents the preliminary results of a larger project for the study of the Egyptian language in Brazil using digital resources. We examined the first stage, Introduction to Classical Egyptian (Middle Egyptian), the first online course for the Egyptian language in Brazil, taking into account the challenging reality of the Egyptological training in the country. Based on the Digital Humanities debate that questions the production and

* Centro de Humanidades - CHAM, Faculdade de Ciências Sociais e Humanas, FCSH, Universidade NOVA de Lisboa, Lisboa, Portugal.

** Universidade de São Paulo - USP, São Paulo, Brasil; Faculdade de Filosofia, Letras e Ciências Humanas, São Paulo. Pesquisadora na University of Oxford - Harris Manchester, Oxford, Inglaterra.

\section{LINHA DÁGUA}


dissemination of knowledge in the human sciences using technological resources, we point out possible ways for the expansion of this project in the Brazilian scenario. In this scope, the discussion about digital platforms and the teaching of Ancient History in Brazil are important elements in the context of this initiative.

Keywords: Egyptology; Digital Humanities; Hieroglyphs; Ancient History; Education.

\section{Introdução}

A Egiptologia, segundo o imaginário popular, é sinônimo de ruínas antigas e solitárias, em meio ao deserto, à espera de arqueólogos para revelarem os seus tesouros e mistérios. Contudo, a transição da Egiptologia de um hobby aristocrático para a sua consolidação como campo científico decorre dos esforços de muitos pesquisadores, mas deve a formação da disciplina acadêmica principalmente aos filólogos e linguistas.

Até meados do século XIX dependíamos do relato bíblico ou de viajantes gregos, romanos e árabes para acessarmos o Egito. Ao facultar-se o aprendizado da língua egípcia, os investigadores adquiriram a capacidade de diálogo com aquela sociedade sem passar pelos filtros de relatos estrangeiros. Restituir ao egípcio a capacidade de falar de si depois de um milênio e meio de silêncio se tornou, portanto, o marco fundador da Egiptologia.

O estudo da língua egípcia antiga clássica, o Egípcio Médio, é uma prerrogativa importante para a formação dos egiptólogos em todo o mundo. O conhecimento dos hieróglifos, com a tradução da Pedra de Rosetta em 1822 por Jean-François Champollion, marcou o início da Egiptologia como disciplina acadêmica. Sua origem filológica, no contexto dos estudos orientais na Europa do século XIX, teve desdobramentos variados na implementação do campo ao redor do mundo, que podem ser medidos até hoje nas diversas escolas da Egiptologia e dos seus centros de pesquisa, localizadas principalmente na Europa e na América do Norte.

Como uma disciplina predominantemente francesa, inglesa e alemã, as gramáticas e métodos de aprendizagem da língua egípcia foram produzido nestes idiomas, trazendo muitos obstáculos àqueles que não eram versados nessas línguas. Para os falantes nativos dessas línguas, existe uma rica oferta de bibliografia para se iniciarem e aperfeiçoarem no estudo de qualquer estágio da língua egípcia.

Para os egiptólogos lusófonos ${ }^{1}$, o aprendizado das línguas modernas é uma ferramenta indispensável à formação e à continuação das pesquisas, mas nem sempre acessível e realizável em curto prazo. Infelizmente, para o estudante brasileiro, as principais gramáticas e manuais de língua egípcia disponíveis foram produzidos em alemão, francês e inglês.

1 O mesmo problema é relatado pelos egiptólogos espanhóis. Contudo, a Egiptologia espanhola produziu materiais próprios há algumas décadas, o que certamente favoreceu os estudantes de língua portuguesa, como é o caso da tradução de Collier e Manley (2000). línguaportuguês

\section{LINHA DÁGUA}


As possibilidades de conhecimento e imersão na língua egípcia clássica e suas variantes (neoegípcio, demótico, copta) precisaram enfrentar uma outra barreira linguística que só muito recentemente vem sendo rompida. Em muitos casos, cabia aos aspirantes da Egiptologia, o trabalho de estudar duas línguas simultaneamente: o egípcio antigo e a língua moderna, precisamente o alemão, francês ou inglês, que atuava como mediadora. O processo de aprendizado exigia o dobro do tempo e de esforço, com sucessivas traduções e reformulações dos enunciados e conceitos.

Neste artigo, apresentamos como estudo de caso o curso Introdução ao Egípcio Clássico (Egípcio Médio), uma iniciativa dos autores em parceria com o Grupo de Trabalho de História Antiga da ANPUH (GTHA/ANPUH) e a Universidade Federal de Santa Catarina (UFSC), ministrado entre Setembro e Novembro de 2020. A partir desse curso, exploramos possibilidades que tenham por objetivo amenizar os desafios encontrados pelos pesquisadores e estudantes de Egiptologia no Brasil. A produção de um método em língua portuguesa certamente contribuiu para a barreira linguística (PEREIRA, 2014, 2016).

Contudo, a realidade brasileira ainda possui inúmeros obstáculos para o desenvolvimento dos estudos sobre o Egito antigo. A extensão territorial, o número reduzido de professores especialistas, principalmente com o conhecimento da língua egípcia, a dificuldade de acesso a periódicos especializados, bibliotecas limitadas e a profunda desigualdade social e educacional no país são elementos que precisam ser levados em conta no nosso esforço de formação.

O curso foi o primeiro disponibilizado em plataforma digital com acesso aberto, ${ }^{2}$ atingindo todas as regiões do Brasil (e Argentina). Voltado para pesquisadores em diversos estágios de formação e professores da área, a proposta do curso foi também ampliar e consolidar redes de colaboração entre especialistas, favorecendo a troca de informações e materiais e, de maneira secundária, abrir oportunidades para a formação e cultivo de laços de cooperação entre os participantes, incluindo aqueles localizados em estados com menos disponibilidade de professores, livros e grupos de estudo. A transposição de barreiras regionais foi favorecida pelo uso das plataformas digitais, possibilitando que as aulas fossem ministradas de Portugal para o Brasil e a Argentina. Discutiremos o curso à luz dos problemas enfrentados pelo uso das tecnologias e plataformas digitais no ensino, mas buscando apontar caminhos para a ampliação do projeto e de iniciativas semelhantes.

2 A playlist com as 10 aulas introdutórias, que cobrem as formas nominais do Egípcio Clássico, estão disponíveis no canal do YouTube do GTHA/ANPUH e podem ser acessadas pelo link: https://www.youtube.com/playlist?list=PLI8rGh6UbR_vOBaIrALDQwiSHSgQ2TleQ 


\section{Egiptologia no Brasil: problemas, desafios e oportunidades}

A Egiptologia no mundo lusófono ainda é uma disciplina em processo de consolidação e carece de instrumentos essenciais para a capacitação dos seus profissionais. Boas bibliotecas e o treinamento em línguas antigas e modernas são fundamentais para a formação profissional na área, além do acesso às fontes primárias (ROCHA, 2014, 2017, 2019).

No caso específico do Brasil, é preciso levar em conta outros aspectos que não podem ser vistos de forma dissociada. O processo de institucionalização do conhecimento sobre o mundo antigo, a 'chegada' do Egito antigo no Brasil e o desenvolvimento do ensino superior nesta disciplina em território nacional, o qual passa pelo debate sobre a desigualdade social contribuíram para o quadro atual da disciplina em solo brasileiro ${ }^{3}$.

O aparecimento tardio da Egiptologia nas universidades não pode ser justificado pela ausência de um interesse pelo Egito antigo ou mesmo pela falta de coleções egípcias no Brasil ${ }^{4}$. O desenvolvimento da chamada História Antiga (onde o Egito se encaixa primordialmente) respondeu a processos específicos no Brasil e que vem sendo avaliados e debatidos na última década (CARVALHO e FUNARI, 2007; GUARINELLO, 2008; SILVA, 2010; SILVA, 2011; FRANCISCO, 2017).

Os textos disponíveis para o ensino da arqueologia, da história e das línguas do mundo antigo estão maioritariamente em língua estrangeira, sobretudo o inglês ${ }^{5}$, o que traz dificuldades de todos os tipos aos professores da área que ensinam na graduação. Apesar da existência de traduções de publicações internacionais, elas nem sempre acompanham a velocidade da produção acadêmica e dos debates produzidos pelos centros de excelência, de modo que o material disponível em língua portuguesa fica sempre desatualizado. Desse modo, os professores de história antiga, por vezes injustamente acusados de elitistas por não disponibilizarem textos em língua portuguesa a estudantes, se veem num terreno complicado para ministrarem seus cursos.

No caso do domínio da língua inglesa, um relatório do British Council já apontava, em 2014, que, aproximadamente, $5 \%$ da população brasileira estava capacitada a interagir com textos complexos em inglês, e que apenas $1 \%$ dos brasileiros possuía fluência na língua ${ }^{6}$. De facto, o quadro se mantém, uma vez que o Brasil figura na $53^{a}$ posição (low proficiency) ${ }^{7}$ do relatório de 2020 apresentado pelo EF English Proficiency Index (EF EPI) - que analisa dados de 2,3 milhões de falantes não nativos de inglês, em 100 países e regiões ${ }^{8}$.

3 Sobre a formação da História Antiga no Brasil ver Funari (2010), Santos, Kolv e Nazário (2017), Santos (2019, 2021, no prelo). Sobre a formação da Egiptologia no Brasil, ver Bakos (2004), Rocha (2014, 2017, 2019).

4 Um panorama geral sobre as coleções egípcias no Brasil é apresentado em Bakos (2004) e Brancaglion (2004).

5 O inglês é o idioma mais utilizado nos grupos de pesquisa e nas publicações internacionais.

6 O relatório, preparado pelo Data Popular Institute, pode ser consultado na sua íntegra através do link: https://www.britishcouncil.org.br/sites/default/files/learning_english_in_brazil.pdf

7 Por comparação, o outro país lusófono dedicado ao estudo da Egiptologia, Portugal, está colocado na $7^{\mathrm{a}}$ posição do mesmo ranking (very high proficiency).

8 https://www.ef.com/wwen/epi/

\section{LINHA DÁGUA}


Como um agravante para esse quadro, a Egiptologia é uma disciplina particularmente exigente quanto ao domínio de bibliografia multilíngue. As obras essenciais, ou seja, o estado da arte e a discussão de todas as temáticas da disciplina obrigam o pesquisador a uma consulta de obras disponíveis em inglês, francês e alemão.

A produção egiptológica em língua portuguesa, além de mínima, é ainda pouco relevante e periférica em relação ao cenário internacional. A formação de um egiptólogo brasileiro exige, portanto, a pronta construção de ferramentas essenciais para o seu ensino na língua portuguesa, associado à aquisição paralela de idiomas estrangeiros. Deste modo, qualquer investigação sobre o Egito que não esteja instrumentalizada com idiomas estrangeiros ficaria circunscrita a referências muito limitadas.

É preciso reconhecer o esforço de acadêmicos brasileiros no ensino da língua egípcia que antecedem à publicação da primeira gramática para a escrita hieroglífica clássica em português (PEREIRA, 2014, 2016) ${ }^{9}$. Ciro Flamarion foi o primeiro acadêmico brasileiro a ensinar a língua egípcia nas universidades brasileiras. Criou e produziu um material de Egípcio Clássico e Neoegípcio e ministrou cursos a um grupo de alunos na Universidade Federal Fluminense, durante a década de 1990, muitos dos quais eram seus alunos de pós-graduação na época. O seu método, entretanto, ainda não foi publicado (SANTOS, 2012). Poucos profissionais replicaram o ensino do egípcio antigo, mesmo com a adição de materiais em língua estrangeira.

Os primeiros a estudarem com o Prof. Ciro foram os professores Marcos Caldas, Julio Gralha, Haydée Oliveira, Marcia Bezerra, Cláudio Prado de Mello e Nely Feitosa, ainda na década de $1990^{10}$. Alguns alunos de Flamarion Cardoso deram continuidade ao ensino de língua egípcia no Rio de Janeiro na década de 2000, mas com público restrito. A Profa. Nely Feitosa organizou cursos na Faculdade São Bento (2010-2013), na Unilasalle (2010-2015) e na pósgraduação da UFRJ em 2018. Marcos Caldas promoveu cursos na UFF (2003-2006) e depois na UFRRJ, como parte das atividades dos seus grupos de pesquisa, e na UFRJ (2018). Entre 2005 e 2006, Moacir Elias Santos ministrou um curso de extensão pela UNIANDRADE, no Paraná. Em 2007, o curso de especialização em História Antiga e Medieval das faculdades Bagozzi, de Curitiba, incluíram um módulo de Língua Egípcia na grade, também ministrado por Santos. O curso posteriormente passou para o ITECNE (atualmente Faculdades Madalena Sofia) e continuou na grade até 2016, quando a carga horária foi incorporada a uma disciplina destinada ao Egito Antigo. Em 2012, o curso de língua egípcia foi oferecido pelo ITECNE, como curso de extensão.

Vale destacar iniciativas do Centro de Estudos Interdisciplinares da Antiguidade (CEIAUFF) e do Grupo de Estudos Egiptológicos Maat, ambos no Rio de Janeiro, que promoveram

9 Em Portugal, a língua egípcia era ensinada na década de 1990 na Universidade Nova de Lisboa pela Profa. Dra. Maria Helena Trindade Lopes e na Universidade de Lisboa pelo Prof. Dr. Manuel Araújo tendo como principal referência a gramática de Gardiner (2012 [1927]).

10 Agradecemos a Nely Feitosa e Moacir Elias Santos por essas informações.

\section{LINHA DÁGUA}


cursos introdutórios. A XII Jornada de Estudos do Oriente Antigo - O Egito Antigo no Terceiro Milênio, em Porto Alegre, realizou um curso intitulado Introdução a Mais Bela Escrita do Mundo: Hieróglifos, organizado pelos professores Margaret Bakos, Júlio Gralha e Moacir Elias Santos. Entre as décadas de 2010 e 2020, o Seshat (Laboratório de Egiptologia do Museu Nacional) também ministrou cursos de extensão com caráter introdutório. Cássio Duarte Araújo, Maurício Schneider e Antonio Brancaglion Jr. ofereceram também cursos de introdução em São Paulo.

O Neoegípcio foi ministrado por Cardoso em 2010 e Liliane Coelho ofereceu o curso para alunos que integravam o projeto de pesquisa sobre as cartas de escribas de Deir el Medina, em Porto Alegre, coordenado por Margarete Bakos. Em 2015 e 2019, empregado os materiais do curso oferecido em Curitiba, Coelho também ministrou um curso de extensão sobre o Egípcio Médio, pelo Núcleo de Estudos da Antiguidade da UERJ.

O esforço de ensinar a língua egípcia ficou concentrado na região sudeste do Brasil, dificultando o acesso para alunos de outros Estados. Até o início da década de 2000, a internet estava ainda sendo implementada no país e o acesso era limitado. Ao mesmo tempo, a dispersão dos grupos de pesquisa e as dificuldades da realidade brasileira na formação de profissionais da Egiptologia fizeram com que poucos alunos seguissem no estudo sistemático do egípcio antigo. Nesse sentido, apesar da relevância da obra de Pereira, o impacto da sua gramática imediatamente após o lançamento, ainda foi limitado no Brasil, o que pode ser justificado pelo reduzido capital humano habilitado a ensinar a língua egípcia clássica.

Mas se o cenário da Egiptologia no Brasil parece bastante desolador até então, é preciso dizer que transformações significativas estão ocorrendo. A primeira delas foi o resultado de concursos públicos e da ampliação de vagas e instituições no Ensino Superior durante a década de 2010 que promoveu a descentralização do eixo Rio-São Paulo (SANTOS, 2017, 2019). Essa expansão, que atingiu todas as regiões do país, criou novos centros de pesquisa dedicados ao Egito antigo e o número de alunos integrantes de programas de pós-graduação também se ampliou graças à expansão de financiamentos para a pesquisa. Um outro elemento foi também o processo - lento - de internacionalização do Brasil na Egiptologia, com o retorno ao país de alunos de pós-graduação tendo formação parcial ou integral no exterior, que aprenderam a língua egípcia como parte de sua formação acadêmica possibilitando parcerias internacionais.

O aumento do número de pesquisadores mudou pouco a realidade da nossa formação, à medida existem elementos estruturais que não foram significativamente transformados (bibliotecas, acesso a periódicos, linhas de financiamento, etc.), mas tem criado oportunidades de colaboração, facilitadas recentemente pelas plataformas digitais. Nesse sentido, a situação da pandemia da COVID-19 acelerou um processo de divulgação de pesquisas, eventos e publicações, em grande parte promovidas pelas redes sociais. Isso também favoreceu a aproximação de pesquisadores de diferentes regiões do país (e do mundo), incluindo também possibilidades de participação do público não-especialista consumir esses conteúdos. É nesse escopo que precisamos examinar os benefícios e limitações das plataformas digitais.

\section{LINHA DÁGUA}




\section{As humanidades digitais e novos desafios para o ensino}

$\mathrm{Na}$ última década, o desenvolvimento das Humanidades Digitais tem aberto novas oportunidades para as mais variadas áreas de pesquisa. Como uma área acadêmica interdisciplinar que fornece metodologias específicas da área das tecnologias digitais para serem incorporadas na investigação nas Humanidades como um todo (HOCKEY, 2004), essa nova frente de trabalho foi particularmente relevante durante o ano de $2020 \mathrm{com}$ a pandemia da COVID-19 em que bibliotecas e instituições de ensino ficaram fechadas em quase todo o mundo pela maior parte do ano acadêmico.

Os inúmeros benefícios do trabalho interdisciplinar e as possibilidades de colaboração não devem diminuir, contudo, a importância das discussões teórico-metodológicas que são próprios das ciências humanas. Ao mesmo tempo, é preciso ter cautela com as promessas de inclusão e acesso aos conteúdos, levando em conta a variedade das realidades sociais e as particularidades de cada contexto de produção do conhecimento (KLEIN , 2015; BROWN, 2020).

Em linhas gerais, as Humanidades Digitais respondem a desafios profissionais e sociais também fora da academia (digitalização de património cultural, novas formas de cultura e de literatura, edição digital, criação de bases de dados, ferramentas de georeferenciamento, modelos em 3D, ambientes virtuais, tratamento de imagens, novos desafios de preservação em museus, arquivos, etc.). Mais do que apresentar uma definição sobre o que são as Humanidades Digitais $^{11}$, nos interessa aqui apontar como alguns dos seus recursos podem favorecer a ampliação de colaborações e do ensino. Nessa linha, Cohen sugere uma definição mais ampla, das Humanidades Digitais como um estímulo para o desenvolvimento de todo o potencial de investigação, ensino, publicação e divulgação das humanidades, através da incorporação de ferramentas, fontes e métodos digitais (COHEN, 2011). Alves (2016, p. 96), por outro lado, não a reduz a uma disciplina, mas a entende como uma comunidade transdisciplinar que amplia a possibilidade de trocas ao mesmo tempo que impacta as estruturas tradicionais em torno das formas de interação e mesmo da formulação de projetos. Mournier (2010) as trata como uma disciplina transversal, portadora dos métodos, dos dispositivos e das perspetivas heurísticas ligadas próprias do universo digital, mas adaptadas à realidade das ciências humanas e sociais.

Se por um lado as Humanidades Digitais englobam o conjunto de pesquisas e experiências que visam facilitar a utilização dos recursos digitais no âmbito das ciências sociais e humanas, elas não se limitam a uma simples transferência do meio. Trata-se de problematizar também o processo de construção do conhecimento. No caso da História, por exemplo, as plataformas digitais re-contextualizam as fontes primárias, e esse processo precisa ser problematizado e discutido. Noiret (2015, p. 33) nos lembra também que o desenvolvimento de

11 Não há uma definição única para o termo. Ver por exemplo: EADH - European Associaiton for Digital Humanities (https://eadh.org/education/digital-humanities-centres); UCLCDH - UCL Centre for Digital Humanities (https://www.ucl.ac.uk/digital-humanities/); https://www.thebritishacademy.ac.uk/blog/what-aredigital-humanities/; http://www.iea.usp.br/en/news/digital-humanities-and-interdisciplinary

\section{LINHA DÁGUA}

Todo conteúdo da Linha D’Água está sob Licença Creative Commons CC -By 4.0. 
uma relação estreita com as tecnologias pode modificar os próprios parâmetros da pesquisa. É preciso reforçar que as Humanidades Digitais devem ser pensadas como uma nova forma de solucionar os problemas da investigação ${ }^{12}$ sem deixar de lado a complexidade as múltiplas modalidades de análise em profundidade, crítica e interpretação (EVANS e REES, 2012; MALERBA, 2017; MOERBECK e ROCHA, 2021, no prelo).

Segundo Guerreiro e Borbinha (2014, p. 73), as Humanidades Digitais são inegavelmente um campo fértil da investigação. Todavia, uma das suas fraquezas é a ausência de modelos genéricos de sistematização (arquivamento) e reutilização (partilha) da informação reunida. A ausência de um modelo único, contudo, pode abrir espaço para o desenvolvimento do campo, acomodando demandas específicas de cada disciplina e seus problemas teóricometodológicos. Alves (2016, p. 103) defende que Humanidades Digitais não necessitam de um processo de institucionalização formal, ou seja, que se transformem numa disciplina independente. A difusão e o aperfeiçoamento dessas ferramentas seriam então inerentes à atualização das humanidades diante de uma nova realidade tecnológica. O autor conclui:

Talvez o conceito de comunidade e o desenvolvimento das suas múltiplas formas de afirmação, como se viu - da prática de investigação, à interação com o mundo para além da academia, passando pela construção dinâmica do conhecimento ou pelos novos métodos de validação do mesmo - possam fazer mais pela difusão e afirmação da qualidade, valência e relevância da investigação em Humanidades com uma componente Digital, do que as tentativas, por vezes forçadas e pouco estruturadas, de formalizar a sua presença no meio académico. (ALVES, 2016, P.103).

Tal posição reflete o modelo defendido por Cordell (2015), no qual as Humanidades Digitais deveriam ser incorporadas naturalmente ao currículo de cada disciplina acadêmica.

O desenvolvimento da internet teve um impacto significativo na produção e circulação do conhecimento. Os meios tradicionais da produção de saberes - o livro e a academia -, foram subvertidos ao mesmo tempo que houve uma transformação profunda na audiência que consome estes conteúdos. Mais ainda, o novo público deu forma a novos hábitos desse consumo, ampliando as possibilidades de interação (NOIRET, 2015).

A fim de garantir e expandir o acesso, é preciso repensar as formas e o tempo de consumo: textos e vídeos curtos, linguagem acessível, organização e distribuição visual das informações passam a ser submetidas a uma nova velocidade de atenção e resposta. $\mathrm{O}$ dinamismo e imediatismo do ambiente virtual trouxeram impactos significativos para o ensino e é preciso enquadrar o debate para além da polarização que coloca a internet como 'boa' ou 'má. ${ }^{13}$

12 Ferramentas de processamento de imagem, criação e curadoria de grandes bases de dados são exemplos comuns que museus e bibliotecas especializadas têm utilizado na preservação de fontes históricas. A criação de modelos em 3D através da fotogrametria e de softwares de GIS também auxiliam a arqueologia no entendimento da paisagem e das fontes materiais. Técnicas não invasivas para obtenção e processamento de imagens têm sido utilizadas em larga escala para o tratamento de restos humanos, o entendimento de técnicas de enterramento, mumificação, etc.

13 Ver o caso da Wikipedia e projetos de educação associados a ela, como por exemplo, Marques (2013, 2019), Louvem e Marques (2013), Moerbeck e Rocha (2021, no prelo).

\section{LINHA DÁGUA}




\section{Ensinando a língua egípcia em ambiente virtual}

O projeto de ensino do Egípcio Clássico examinado neste artigo está ainda em fase experimental, mas teve resultados importantes no seu primeiro módulo em 2020, os quais serão discutidos a seguir e que devem servir de base para as próximas etapas. Nosso objetivo com este projeto é, por um lado, a consolidação da gramática como ferramenta de trabalho nas universidades brasileiras, somando-se à disponibilização de uma antologia de fontes e glossário ao acesso público, digital e gratuito. De outro, tem como ambição a promoção de um ambiente mais colaborativo entre os egiptólogos do país, à medida que pesquisadores podem compartilhar das mesmas ferramentas, recursos e multiplicar o ensino de língua em seus departamentos, consolidando o conhecimento tradicional da Egiptologia com os debates desenvolvidos no Brasil.

A promoção do aprendizado da língua egípcia antiga em Português é uma tentativa de acelerar a curva de aprendizagem e de minimizar os obstáculos de se aprender uma língua antiga em um idioma estrangeiro - experiência que os dois autores deste texto enfrentaram ${ }^{14}$. No caso específico de Pereira, que aprendeu todos os estágios da língua egípcia através de professores e bibliografia alemã, o processo, por vezes frustrante, de acompanhamento das aulas ajudou-o a desenvolver metodologias de estudo e a escrever os conteúdos gramaticais em português para estudo próprio. Tais metodologias eram completamente empíricas e foram ajustadas segundo a conveniência de cada lição aprendida. Esse longo processo de aprendizagem se desdobrou em atividades de ensino em Portugal, onde o autor teve a oportunidade de aplicar sua própria metodologia de aprendizado e aperfeiçoá-la como método de ensino em sala de aula desde $2011^{15}$. A ausência completa de material didático em língua portuguesa forçou-o a preparar apostilas para o ensino da gramática egípcia. Esse material era constantemente revisto e, eventualmente, expandido. Como resultado do esforço, em fins de 2014 foi publicada a primeira edição da primeira gramática de língua egípcia em português (PEREIRA, 2014, 2016) ${ }^{16}$.

O principal objetivo dessa obra era permitir ao estudante lusófono o aprendizado da gramática egípcia na sua própria língua materna. Embora ainda não exista um dicionário de Egípcio-Português, o vocabulário existente na obra soma cerca de 900 palavras traduzidas, em adição às tabelas de pronomes, preposições, numerais e calendários. Há ainda uma lista com mais de 700 hieróglifos egípcios descritos e analisados na secção de apêndices, disponíveis para consulta. A gramática foi concebida como um desmistificador da língua egípcia, desfazendo a ideia de que, para se entender os textos egípcios, é preciso algum tipo de iniciação ou genialidade.

14 O ensino de grego e latim já conta com a experiência de profissionais que têm ministrado aulas no ambiente virtual para pequenos grupos ou individualmente. A oferta de materiais em língua portuguesa é maior e o debate sobre iniciativas de ensino também tem sido feito por especialistas. Sobre outros projetos de popularização de grego e latim, ver o Projeto Minimus; também Sumares (2014) e Santos (2020).

15 R. G. G. Pereira ensina a gramática egípcia clássica para turmas de graduação e pós-graduação em História na Universidade Nova de Lisboa desde 2011.

16 A obra foi revista, corrigida e expandida em 2016, passando o texto para o novo acordo ortográfico. Entretanto, a Universidade Federal Fluminense (Brasil) já na década de 1990 utilizava o material de autoria do Prof. Dr. Ciro Flamarion Cardoso (UFF), que ainda não foi publicada.

\section{LINHA DÁGUA}

Todo conteúdo da Linha D’Água está sob Licença Creative Commons CC -By 4.0. 
Com base nessa experiência, o curso de Introdução ao Egípcio Clássico (Egípcio Médio) foi pensado para o público brasileiro numa tentativa de facilitar o acesso ao aprendizado da língua e possibilitar sua multiplicação através do ambiente virtual. Das etapas envolvidas no seu planejamento, destacamos duas frentes. A primeira diz respeito ao aspecto operacional, com o apoio institucional e a escolha das plataformas digitais para nas aulas síncronas e assíncronas. O segundo elemento importante foi a definição do público-alvo, tendo em vista as demandas da área no contexto brasileiro.

Inicialmente foi feita uma sondagem com os professores especialistas em Egito antigo no Brasil a fim de se ter ideia da possível demanda interessada, principalmente dos laboratórios de pesquisa espalhados pelo país. Tínhamos em mente atender alunos inscritos em programas de pós-graduação (Mestrado e Doutorado) que precisavam do conhecimento da língua para desenvolver seus projetos de pesquisa e também os professores especialistas que poderiam multiplicar o ensino da língua em seus grupos.

Com uma estimativa inicial dos colegas entre 20 e 30 alunos no máximo, de todo o Brasil, planejamos o curso em duas etapas. A parte assíncrona consistia num vídeo com a aula expositiva, baseado no conteúdo da gramática de Pereira e seguindo as lições e divisões de conteúdo apresentada no método. ${ }^{17} \mathrm{O}$ segundo momento da aula seria síncrono, a fím de garantir a discussão dos conteúdos, a correção dos exercícios e a possibilidade de prática de leitura a partir de fontes primárias (estelas, inscrições monumentais, funerárias, etc.) ${ }^{18}$. Paralelamente, outros materiais de apoio seriam disponibilizados ao longo do curso.

Com o apoio da Universidade Federal de Santa Catarina (UFSC) e do GTHA/ANPUH foi possível credenciar o curso como um projeto de extensão, emitindo certificado aos alunos, o qual poderia ser incluído em suas atividades de produção acadêmica. Num outro nível, a divulgação do curso aproveitou da rede de comunicação do GTHA/ANPUH (lista de emails, redes sociais), que inclui todos os professores de História Antiga no Brasil e muitos alunos. A divulgação em larga escala foi importante, mas deixou de lado outros interessados. ${ }^{19} \mathrm{Na}$ tentativa de ampliar o acesso e não prejudicar outros pesquisadores, foi acordado que o material das aulas expositivas ficaria disponível no canal do GTHA/ANPUH no YouTube, uma plataforma digital de fácil acesso e gratuita.

17 A aquisição da gramática era pré-requisito para o curso. A editora disponibilizou também a versão em e-pub. Por conta do contexto da pandemia em 2020, essa era uma opção mais barata e que não dependia da entrega dos correios, facilitando o acesso a todos os alunos.

18 Os encontros foram feitos pela plataforma Google Meet. O link para o encontro síncrono era enviado 15 minutos antes do início da aula. Os alunos recebiam as vídeo-aulas uma semana antes da aula síncrona e tinham este período para realizar os exercícios da gramática.

19 Apenas no primeiro dia de divulgação oficial, o projeto recebeu mais de 120 pedidos de inscrição. Com a alta procura, foi preciso fazer um processo de seleção que levasse em conta os projetos de pesquisa. Os critérios incluíam a afiliação a um programa de pós-graduação, projeto de pesquisa que envolvia o conhecimento de língua egípcia clássica e o estágio de desenvolvimento da pesquisa. Houve procura do público não-especialista e pesquisadores dedicados ao Egito greco-romano.

\section{LINHA DÁGUA}


O curso (Fig.1) contou com 27 departamentos em 25 universidades (uma das quais, argentina, ver Gráfico 1). Foram 44 inscritos, divididos em duas turmas para as atividades síncronas. Concluíram o curso 32 alunos, respeitando o critério de presença das aulas síncronas (75\%) e a realização da atividade de avaliação final, que consistia na transliteração e tradução de um texto de uma estela.

Figura 1. Instituições participantes do curso Introdução ao Egípcio Clássico (Egípcio Médio) Formas Nominais.

\section{ALUNOS DO CURSO DE 2020}

피 Docentes Universitários 피 Doutorandos e Mestrandos

Universidad de Mar del Plata (Argentina)

Universidade Federal do Rio Grande do Sul

Universidade Federal de Pelotas

Universidade Federal de Londrina

Universidade Federal do Paraná/ ITECNE

Universidade Federal do Mato Grosso do Sul

Museu de Arqueologia e Etnologia/ USP

Universidade de São Paulo

Pontifícia Universidade Católica - São Paulo

USP -Dep. De História

Centro Universitário Internacional (UNINTER)

Centro Universitário Celso Lisboa

Museu Nacional/ UFRJ

Universidade Federal do Rio de Janeiro

Universidade Federal Rural do Rio de Janeiro

Universidade Federal do triângulo Mineiro

Universidade Federal do Espírito Santo

Universidade Estadual do Sudoeste da Bahia

Universidade de Pernambuco - CMN

Universidade Federal da Paraíba

Universidade Estadual do Rio Grande do Norte

Universidade Federal do Rio Grande do Norte

Universidade Estadual do Ceará

Universidade Estadual Vale do Araraú - Ceará

Universidade Estadual do Maranhão

Universidade Federal do Maranhão

Universidade Federal do Amazonas
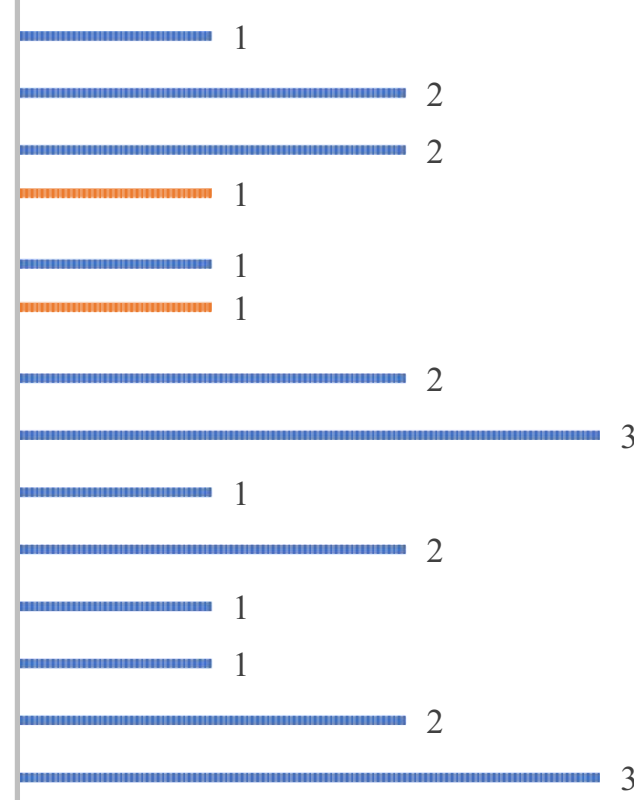

3
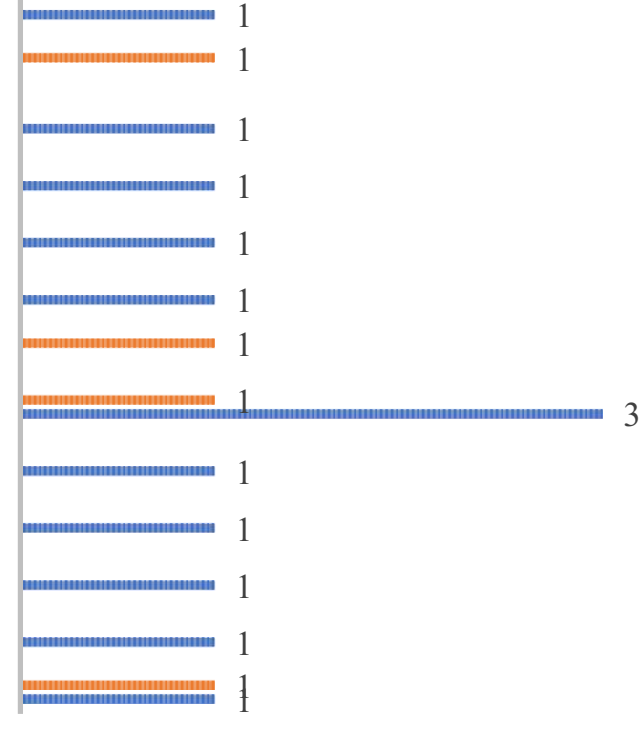

2

3

Fonte: elaborado pelos autores.

\section{LINHA DÁGUA}

Todo conteúdo da Linha D’Água está sob Licença Creative Commons CC -By 4.0. 
Ainda que as vídeo-aulas sejam um elemento importante da aprendizagem, elas são apenas uma etapa do processo e devem servir como ponto de partida para o estudo individual. Sabemos da importância dos encontros síncronos e da necessidade de acompanhamento nos exercícios, principalmente para que os alunos adquiram segurança e familiaridade com a estrutura da língua a fim de lidar com a complexidade do processo de transliteração e tradução. As atividades síncronas tiveram como objetivo também o desenvolvimento de um repositório de fontes (estelas, portas-falsas, etc.) que constituem o principal material para o desenvolvimento das competências de leitura (transliteração e tradução).

Uma vez que tínhamos conhecimento dos projetos de pesquisa dos alunos, procuramos incorporar exemplos que pudessem ser úteis para seus respectivos projetos, discutindo também a importância do contexto e do suporte material das fontes egípcias, além da relação intrínseca entre texto e imagem. Os alunos tiveram, ao longo do curso, a possibilidade de explorar outros elementos das fontes, ainda que de forma inicial num curso introdutório, mas que permitiram ampliar o escopo das suas leituras e atividades de pesquisa ${ }^{20}$. Um elemento que consideramos fundamental foi a participação coletiva no repositório de referências: todos tinham acesso ao drive compartilhado e podiam fazer o upload de referências que fossem relevantes para o grupo.

Espera-se que este repositório seja ampliado no decorrer do módulo 2 (Formas Verbais) para, futuramente, constituir um banco de fontes e um glossário com acesso aberto em plataforma digital. Um dos elementos importantes para a concretização desse projeto é o fortalecimento da Egiptologia nas instituições de ensino superior brasileiras e de colaborações entre os especialistas lusófonos. O apoio do GTHA/ANPUH é também essencial a fim de otimizar os esforços e espaços colaborativos, como foi feito nessa primeira etapa.

Entendemos que o projeto foi um híbrido de atividades síncronas e assíncronas, como a maior parte do ensino durante o ano de 2020. Reconhecemos, nesse escopo, que um projeto de ensino de língua à distância requer outros recursos, tanto dos professores, como de ferramentas empregadas. As vídeo-aulas, aplicativos para memorização, dicionários online e o repositório para atividades e referências, sem incluir a gramática são complementos para a aprendizagem e devem ser vistos como ferramentas. Os encontros síncronos eram o momento crucial do curso onde se privilegiava a interação entre os colegas e destes com os professores. Contudo, a interação no ambiente virtual fica limitada muitas vezes ao tipo de suporte utilizado (computador ou celular, qualidade da câmera, microfones). Além disso, é preciso levar em conta um outro tipo de organização da comunicação (quem fala, quando fala, como sinalizar, como interromper), que é muito distinto quando feito presencialmente. Apesar da estabilidade da ferramenta, muitas vezes, alunos não conseguiram participar por problemas de conexão da internet e falta de energia elétrica.

20 Muitos alunos nos procuraram individualmente com questões específicas de tradução das fontes que estavam trabalhando. Ainda que o curso não permitisse um conhecimento amplo e rápido do egípcio antigo, muitos se arriscaram mais com suas próprias traduções e a participação dos professores foi bastante pontual.

\section{LINHA DÁGUA}


O potencial para o uso de plataformas e ferramentas digitais na Egiptologia já é conhecido e explorado no exterior. Dicionários, coleções de museus com acesso aberto, palestras e cursos em ambiente virtual são elementos importantes que facilitam colaborações e o processo de internacionalização. Mais ainda, é preciso considerar que muitos destes projetos pressupõem o acesso de conteúdos pelo grande público, de modo que a linguagem nestas plataformas não fica restrita ao público especialista. No caso dos conteúdos relacionados a textos, como dicionários e bases de dados, é preciso que o indivíduo tenha familiaridade com as fontes e conhecimento da língua e da escrita. Uma formação inicial que instrumentalize a leitura do texto egípcio não se restringe necessariamente ao ambiente universitário e pode ser realizada em outros modelos, como é o caso da Egypt Exploration Society (EES) em Londres, que há muitos anos vem oferecendo cursos de Egípcio Clássico para o grande público ${ }^{21}$.

No mundo lusófono, os trabalhos das universidades têm pouco alcance com o público não-especialista. No entanto, o uso das redes sociais pelos pesquisadores tem trazido experiências de sucesso na divulgação de conteúdos egiptológicos, tanto para o público especialista como para os interessados. O Instagram e o Facebook, por exemplo, hospedam contas individuais e grupos de pesquisa que compartilham informações sobre o Egito antigo e a Egiptologia e que podem operar de forma também de forma combinada, ampliando o impacto de alcance ${ }^{22}$.

Iniciativas de colaboração têm se mostrado frutíferas na nova geração de investigadores falantes do Português, no Brasil, em Portugal e com a progressiva aproximação entre os dois países. Se as dificuldades são compartilhadas na formação de profissionais da área e na escassez de recursos financeiros, é preciso que a internacionalização fortaleça a produção e a circulação dos conteúdos em língua portuguesa, trazendo benefícios a médio e longo prazo.

\section{Considerações finais}

O projeto aqui apresentado surgiu de uma oportunidade de fomentar um diálogo entre docentes e investigadores em diferentes estágios de formação na área de Egiptologia no Brasil. Nesse mérito, acreditamos que o curso Introdução ao Egípcio Clássico (Egípcio Médio) pode contribuir para repensarmos práticas de ensino e colaboração tanto entre pesquisadores

21 O Reino Unido possui diversas sociedades que fazem um trabalho importante de divulgação do conhecimento egiptológico para o público interessado, convidando professores e palestrantes especialistas na área. O caso da EES é interessante, pois ela promove também pesquisa, escavações, conferências e um importante trabalho de com arquivos. Para informações sobre a história e os objetivos da fundação ver: https://www.ees.ac.uk/

22 Destaco aqui as iniciativas dos laboratórios brasileiros MAAT (UFRN) e Seshat (MN/UFRJ) e das contas no Instagram dos pesquisadores Inês Torres (Harvard University; @umaegiptologaportuguesa), Rogério Sousa (Universidade de Lisboa; @egiptologiaflul). Daniela Martins (University of Liverpool; @waysofhorus) reúne e divulga informações de conferências, seminários e outras atividades promovidas por egiptólogos também em língua estrangeira, num trabalho semelhante feito pelo EEF (Electronic Egyptological Forum). O trabalho de Marcia Jamile no Brasil, promove o canal Arqueologia Egípcia que tem como principal foco o público não especialista (youtu.be/NxPYOMCAkKY).

\section{LINHA D'ÁGUA}


brasileiros, mas também no ambiente lusófono. A apresentação da primeira fase do projeto deve servir para uma observação crítica do emprego de ferramentas e estratégias de ensino digitais voltadas para a capacitação de um quadro de docentes e investigadores em formação.

Consideramos a realidade brasileira, país que apresenta dimensões físicas continentais e a existência de dezenas de laboratórios e departamentos dedicados ao estudo do mundo antigo, onde a investigação de temáticas egiptológicas têm crescido nos últimos anos. A distância física entre as instituições, espalhadas pelo território brasileiro, já dificulta o contato presencial de seus integrantes, principalmente tendo em vista o custo para se viajar dentro do país, o valor das bolsas de Mestrado e Doutorado pagos pelas agências financiadoras e os recursos limitados para a realização de eventos e atividades acadêmicas, que em geral não incluem os alunos da pós-graduação. O quadro se agravou com a pandemia de COVID-19 em 2020, mas também abriu possibilidades para a comunidade acadêmica.

Entendemos que um projeto de ensino a distância requer recursos e treinamentos específicos, sobretudo com tecnologias digitais que promovam atividades de interação. Se por um lado os recursos para o ensino a distância ainda são escassos e problemáticos no Brasil, acreditamos que as plataformas digitais também podem favorecer a aprendizagem e a cooperação, principalmente para a Egiptologia, ainda em estado embrionário no Brasil.

Os recursos digitais utilizados no projeto (vídeo-aulas, repositório de referências e atividades, aplicativos de memorização, plataforma para encontros síncronos) cumpriram um papel importante, permitindo o ensino de língua egípcia no país em larga escala e a aproximação entre investigadores. Ao mesmo tempo, essas ferramentas não substituem a prática docente e a necessidade de investimento sistemático no estudo do egípcio antigo (memorização de vocabulário, formas nominais, entendimento da estrutura da língua, etc.), principalmente com a leitura das fontes. Estes recursos permitem o armazenamento e o fácil compartilhamento dos conteúdos, o que pode auxiliar colegas que se disponibilizem a ministrar essas aulas no futuro.

\section{Agradecimentos}

Agradecemos aos Professores Alex Degan (UFSC), Dominique Santos (FURB) e Fabio Morales (UFSC), coordenadores do GTHA/ANPUH pelo apoio incondicional neste projeto. Nely Feitosa (UFRRJ), pelas informações sobre os cursos e em especial ao Prof. Moacir Elias Santos (UNIANDRADE) pelo diálogo aberto e colaborativo no planejamento dos cursos de língua e por fazer a ponte com colegas egiptólogos no Brasil. Agradecemos aos alunos e colegas que participaram dessa iniciativa e têm nos ajudado no aperfeiçoamento deste projeto.

\section{LINHA DÁGUA}




\section{Referências}

ALVES, D. "As Humanidades Digitais como uma comunidade de práticas dentro do formalismo académico: dos exemplos internacionais ao caso português". Ler História, 69, 2016, p. 91-103. https://journals.openedition.org/lerhistoria/2496

BAKOS, M. M. (ed.). Egiptomania: o Egito antigo no Brasil. São Paulo: Paris Editorial, 2004.

BRANCAGLION, A. “As coleções egípcias no Brasil” In BAKOS, M. (org.), Egiptomania: o Egito antigo no Brasil. São Paulo: Paris Editorial, 2004, p. 31-41.

BROWN, K. The Routledge Companion to Digital Humanities and Art History. [s.1.]: Routledge, 2020.

CARVALHO, M. M.; FUNARI, P. P. A. "Os avanços da História Antiga no Brasil: algumas ponderações”. História, v. 26, n. 1, 2007, p. 14-19.

COLLIER, M.; MANLEY, B. Introducción a los Jeroglíficos Egipcios. Ilustraciones de Richard Parkinson. Versión de José R. Pérez-Accino. Madrid: Alianza Editorial, 2000.

EVANS, L., REES, S. “An interpretation of digital humanities". In BERRY, D. M. (Ed.) Understanding digital humanities. Houndmills, Basingstoke, Hampshire: Palgrave Macmillan, 2012, p. 21-41.

FRANCISCO, G. S. “O Lugar da História Antiga no Brasil”. Mare Nostrum, 8, 2017, p. 3061.

FUNARI, P. P. A. "Ancient Egypt in Brazil: A Theoretical Approach to Contemporary Uses of the Past". Journal of the World Archaeological Congress, 6, n. 1, 2010, p. 48-61.

GARDINER, A. H. Egyptian grammar: being an introduction to the study of hieroglyphs, Oxford: Griffith Institute, 2012 [1927].

GUARINELLO, N. "A Morphology of ancient History from a tropical, half-European Viewpoint" In FUNARI, P. P. A.; GARRAFONI, R. S.; LETALIEN, B. L. (org.), New Perspectives on the Ancient World: Modern Perceptions, Ancient Representations. Oxford: Archeopress, 2008, p.1-7.

GUERREIRO, D. M., BORBINHA, J. L. "Humanidades Digitais: Novos desafios e oportunidades" Cadernos BAD - Informação. Sociedade. Cidadania, n. 1, 2014, p. 63-78. https://www.bad.pt/publicacoes/index.php/cadernos/article/view/1060

HOCKEY, S. "The History of Humanities Computing”. In: SCHREIBMAN, S., SIEMENS, R., UNSWORTH, J. (Eds.) Companion to Digital Humanities. Oxford, Blackwell, 2004, p. 3-19.

KLEIN, J. T. Interdisciplining Digital Humanities: Boundary Work in an Emerging Field. Ann Arbor: University of Michigan Press, 2015.

LOUVEM, O.; MARQUES, J.B. A Wikipédia como diálogo entre universidade e sociedade: uma experiência em extensão universitária. Anais do XIX Workshop de Informática na Escola (WIE 2013): p. 70-79.

MALERBA, Jurandir . Os historiadores e seus públicos: desafios ao conhecimento histórico na era digital. Revista Brasileira de História. São Paulo, v. 37, nº 74, 2017, p. 135-154.

MARQUES, J.B. Representação e visibilidade do mundo antigo na Wikipédia: gargalos e soluções. Revista do Museu de Arqueologia e Etnologia, 32 , 2019, p. 2-17

\section{LINHA DÁGUA}


MARQUES, J.B. Trabalhando com a História Romana na Wikipedia: uma experiência em conhecimento colaborativo na universidade. Revista História Hoje, 2, n. 3, 2013, p. 329-346.

MOURNIER, P. "Manifeste des Digital Humanities" in: Journal des Anthropologues 122 -123, 2010, p. 447-452. https://journals.openedition.org/jda/3652

MOERBECK, G.; ROCHA, T. Da Antiguidade ao mundo atual: as dimensões da História Antiga e os seus públicos. In: MELO, Rosilene; MENESES, Sônia; WANDERLEY, Sonia. Coleção Ensino de História. Volume: História Pública e Ensino. São Paulo: Letra \& Voz, 2021 (no prelo).

NOIRET, S. “História Pública Digital”. Liinc em Revista, v. 11, n.1, 2015, p. 28-51.

PEREIRA, R. G. G. Gramática Fundamental de Egípcio Hieroglifico. Lisboa: Chiado, 2014, 2016.

ROCHA, T. "Brazilian Egyptology. Reassessing colonialism and exploring limits" In NAVRATILOVA, H.; GERTZEN, T. L.; DODSON, A.; BEDNARSKI, A. (org.). Towards a History of Egyptology. Proceedings of the Egyptological Section of the $8^{\text {th }}$ ESHS Conference in London, 2018. Münster: Zaphon, 2019, p. 127-146.

ROCHA, T. "Tropical Egypt: The Development of Egyptology in Brazil and its Future Challenges". In LANGER, C. (org.), Global Egyptology: Negotiations in the Production of Knowledges on Ancient Egypt in Global Contexts. London: Golden House Publications, 2017, p. 161-171.

ROCHA, T. "O sorriso da esfinge: reflexões sobre o ensino do Egito antigo no Brasil" In LEMOS, R. (org.) O Egito Antigo. Novas contribuições brasileiras. Rio de Janeiro: Multifoco, 2014, p. 279-299.

SANTOS, D. O. "Ensino de História Antiga no Brasil e o debate da BNCC". Outros Tempos, v.16, n. 28, 2019, p. 128-145.

SANTOS, D. O. "De tablet para tablet - novas ferramentas para a pesquisa e o ensino da História das culturas cuneiformes na era digital". Revista Tempo e Argumento, 6, n. 12, 2014, p. 212 241.

SANTOS, D. O; KOLV, G.; NAZÁRIO, J. J. “O Ensino e a Pesquisa em História Antiga no Brasil: reflexões a partir dos dados da Plataforma Lattes". Mare Nostrum - Estudos sobre o Mediterrâneo Antigo, 8, 2017, p.115-153.

SANTOS, D.O.; SANTOS, D. G. "O projeto Paideia: Ensinando grego antigo no município de Blumenau (SC)". Nunt Antiquus, Belo Horizonte, 16, n. 1, 2020 p. 193-218.

SANTOS, M. E. "Estelas, Hieróglifos e Ciro Flamarion Cardoso: Uma contribuição ao desenvolvimento da Egiptologia no Brasil". In: ARAÚJO, S.R.R; LIMA, A.C. (orgs.) Um combatente pela história: Professor Ciro Flamarion Cardoso. Rio de Janeiro: Vício de Leitura, 2012, p. 105-123.

SILVA, G. J. "Os avanços da História Antiga no Brasil”. Anais do XXVI Simpósio Nacional de História-ANPUH, 2011, p. 1-31.

SILVA, S. C. "Aspectos do Ensino de História Antiga no Brasil: algumas observações". Alétheia 1, 2010, 145-55. 


\section{Links da Internet}

COHEN, D. "Defining Digital Humanities, Briefly", 2011 - (acesso em 17/12/2020). http://dancohen.org/2011/03/09/defining-digital-humanities-briefly/

CORDELL, R. "How Not to Teach Digital Humanities", 2015 - (acesso em 17/12/2020). https:/ryancordell.org/teaching/how-not-to-teach-digital-humanities/

EADH - European Associaiton for Digital Humanities - (acesso em 15/01/2020). https://eadh.org/education/digital-humanities-centres

EEF - The Egyptologist's Eletronic Forum - (acesso em 15/01/2020).

https://www.ees.ac.uk/

EES - Egyptian Exploration Society - (acesso em 15/01/2020).

https://www.ees.ac.uk/

EF English Proficiency Index - 2020 - (visitado em 19/12/2020). https://www.ef.com/wwen/epi/

Learning English in Brazil - British Council (São Paulo, 2014) - (acesso em 20/12/2020). https://www.britishcouncil.org.br/sites/default/files/learning_english_in_brazil.pdf

Instagram - (acesso em 20/01/2020).

Daniela Martins (University of Liverpool: @waysofhorus);

Inês Torres (Harvard University: @umaegiptologaportuguesa);

Rogério Sousa (Universidade de Lisboa: @egiptologiaflul).

Laboratório MAAT - UFRN - (acesso em 15/01/2020).

http://maatufrnhome.blog/

Laboratório SESHAT - MN-UFRJ - (acesso em 15/01/2020).

https://seshat.museunacional.ufrj.br

PEREIRA, R.G.; ROCHA, T.; DEGAN, A.; SANTOS, D.; MORALES, F. Como se faz um Egiptólogo? Uma conversa com Thais Rocha da Silva e Ronaldo G. Gurgel Pereira - (acesso em 20/12/2020).

https://www.youtube.com/watch?v=khm1yrvGhvA

PEREIRA, R.G.; ROCHA, T. Introdução ao Egípcio Clássico (Egípcio Médio) - Formas Nominais.

https://www.youtube.com/playlist?list=PLI8rGh6UbR_vOBaIrALDQwiSHSgQ2TleQ

Projeto Minimus, ano II: O grego e o latim no Ensino Fundamental Projeto de Cultura e Extensão da PrCEU da USP. Programa de Pós Graduação em Letras Clássicas (FFLCH-USP), 2019. http://ppglc.fflch.usp.br/node/390

SUMARES, G. "Nova Vida para as Línguas Mortas". Revista Cultura e Extensão USP. Setembro, v. 11, Suplemento, 2014, p. 12-16 - (acesso em 15/01/2020).

http://www.calameo.com/read/001358971215118480e98

\section{LINHA DÁGUA}


UCLCDH - UCL Centre for Digital Humanities - (acesso em 15/01/2020).

https://www.ucl.ac.uk/digital-humanities/

https://www.thebritishacademy.ac.uk/blog/what-are-digital-humanities/

http://www.iea.usp.br/en/news/digital-humanities-and-interdisciplinary

\section{YouTube}

Marcia Jamile “Arqueologia Egípcia” - (acesso em 20/01/2020).

https://www.youtube.com/channel/UCGv1ImAroULYoQTCt1RpzxA

Recebido: 02/02/2021.

Aprovado: 16/03/2021.

\section{LINHA DÁGUA}

